\title{
Use of Integrated Observations to Improve 0-36 h Flood Forecasting: Development and Application of a Coupled Atmosphere-Hydrology System in the Nanpan River Basin, China
}

\author{
Lei WANG \\ Department of Civil Engineering, The University of Tokyo, Japan \\ Key Laboratory of Tibetan Environment Changes and Land Surface Processes, \\ Institute of Tibetan Plateau Research, Chinese Academy of Sciences, China \\ Toshio KOIKE \\ Department of Civil Engineering, The University of Tokyo, Japan \\ Man WANG, Jianyu LIU, Jihua SUN \\ Yunnan Institute of Meteorology, China Meteorological Administration, China \\ Hui LU \\ Department of Civil Engineering, The University of Tokyo, Japan \\ Center for Earth System Science, Tsinghua University and Key Laboratory of \\ Numerical Simulation for Earth System, Ministry of Education, Beijing, China

\section{Hiroyuki TSUTSUI, Katsunori TAMAGAWA} \\ Department of Civil Engineering, The University of Tokyo, Japan \\ and \\ Xiangde XU \\ Chinese Academy of Meteorological Science, China Meteorological Administration, China \\ (Manuscript received 18 February 2011, in final form 24 November 2011)
}

\begin{abstract}
The accuracy of $0-36 \mathrm{~h}$ real-time flood forecasting is largely determined by the quantitative precipitation forecasts (QPFs), but convective weather remains a significant challenge for numerical weather prediction systems. Therefore, it is crucial to improve the QPFs' accuracies to predict and prevent flash flood disasters.
\end{abstract}

Corresponding author: Lei Wang: River Lab, Department of Civil Engineering, The University of Tokyo, 7-3-1, Hongo, Bunkyo-ku, Tokyo 113-8656 Japan.

E-mail: wang@hydra.t.u-tokyo.ac.jp

(C) 2012, Meteorological Society of Japan 
A coupled atmosphere-hydrology system with the WRF model (together with a three-dimensional variational data assimilation system, 3DVAR) and a distributed biosphere hydrological model (WEB-DHM) is described. This system was then applied to the flood forecasting of the Nanpan River Basin (Yunnan province, China) for 1 July 2008. Based on the available observations (230 surface meteorological sites, 10 conventional Radiosonde sites, and 8 ground-based GPS stations), a series of experiments were conducted with the WRF-3DVAR to investigate the contributions of different observations to QPF accuracy and flood forecasting. Forced with the observations or the WRF model outputs, WEB-DHM predicts stream-flow at the basin outlet. The overall better performance by the assimilation experiments over the no assimilation case has been clearly demonstrated in the predictions of the 0-36 h heavy rainfall (magnitude and spatial pattern) and flash flood occurrence (peak value and time). The WRF-3DVAR only assimilating GPS data performs poorly, showing the necessity to improve both the assimilation technique and the spatial resolution for the operational numerical weather forecasts. To our knowledge, this work is the first to utilize comprehensive observations around the Tibetan Plateau with a coupled atmosphere-hydrology system to improve short-term flood predictions.

\section{Introduction}

Flooding is a pervasive natural hazard, which causes human suffering and loss. Floods impact over half a billion people every year worldwide and could impact two billion by 2050 (United Nations University 2004). As much as $44 \%$ of all flood disasters worldwide and $93 \%$ of flood-related deaths in the decade 1988-1997 occurred in Asia; however, most Asian countries, particularly the developing ones (including China), currently lack reasonable operational flood-prediction systems to provide timely and meaningful flood forecasts and warnings. The resolution of this urgent issue requires research and further improvement of the collaboration between meteorological and hydrological services (see Lettenmaier et al. 2006).

Accurate flood forecasts in river basins require (a) a hydrological model to accurately translate precipitation and other surface meteorological conditions into runoff entering river channels, and predict river routing in the channel system, and (b) an atmospheric model to provide reliable numerical weather predictions (NWPs). In recent years, there have been improvements of flood forecasts by the integration of the knowledge of the atmospheric and hydrological communities. In particular, much attention has been paid to "one-way" coupling between atmospheric and hydrological models for streamflow forecasts (e.g., Yu et al. 1999; Lin et al. 2002; De Roo et al. 2003; Benoit et al. 2003; McGuire et al. 2006; Amengual et al. 2008; Diomede et al. 2008; Zhao et al. 2009; Ma et al. 2010).

With the evolution of atmospheric modeling and computing performance, spatial resolution of atmospheric models is now typically a few kilometers, which is compatible with that of hydrological simulations in river basins. On the other hand, short-term flood forecasting largely depends on the quality of deterministic quantitative precipitation forecasts (QPFs), which because of the loss of atmospheric predictability have large uncertainties when going down to small spatial and temporal scales (Diomede et al. 2008).

By using one-way coupling of the state-of-the-art hydrological and atmospheric modeling systems to predict short-term flood disasters, this work aims at providing a test-bed for operational real-time flood forecasts for the Yunnan province of China. This area and other provinces along the Yangtze River Basin (e.g., Sichuan and Guangxi) have had a number of recorded flood disasters.

Due to its unique topography, the Tibetan Plateau, the largest and highest plateau in the world, is crucial to the global water and energy cycles, (Xu et al. 2008a). The Plateau acts as an atmospheric pump which attracts warm and moist air from both Indian and western Pacific Oceans ( Ma et al. 2008), and the atmospheric energy and water vapor transport and convergence are further complicated and intensified by the effect of East Asian monsoon circulation (CAMS et al. 2009).

Because the importance of the Plateau in flood disasters in both China and Japan, joint ChineseJapanese work in 1979, and again in 1998 highlighted the need for a set of more permanent and operational observation networks over the plateau. Consequently, a New Integrated Observational System supported by the China-Japan Joint International Co-operation Project over the Tibetan Plateau (NIOST) was implemented in 2005 and completed in 2009 (CAMS et al. 2009). The NIOST observational network provides a mechanism for transferring research results from field experiments into forecast capability, as well as enhancing research activities by providing routinely available 
long-term datasets (Xu et al. 2008b). The observation network covers most of the Tibetan Plateau, a large portion of the Yunnan province (southeast of Tibet; see Fig. 1a), and some portions of Sichuan, Guangxi, and other provinces along the Yangtze River Basin (Xu et al. 2008b). NIOST comprises several observational platforms, including GPS, GPS sounding (radiosondes with GPS tracking), automated weather stations (AWS), PBL towers, wind profilers, and satellites. It is expected that assimilating satellite remote sensing and surface observation capabilities will be enhanced, to improve the NWPs for the disaster warning in these regions.

The objective of this study is to illustrate improved predictability of heavy-rain induced flash floods in an eastern ambient region of the Tibetan Plateau (Nanpan River Basin, Yunnan province, China; Fig. 1a) by assimilating integrated observations (Fig. 1b) into NWPs for achieving better initial data-fields. "By the provision of more accurate flood forecasts and thus the potential reduction of flood-related disasters, the socio-economic benefits from this China-Japan cooperation project can be clearly demonstrated. In this study, the 36-h real-time flood forecasting from 01 July 2008 in the Nanpan River Basin, using the Advanced Research Weather Research and Forecasting Model (WRF; Skamarock et al. 2005) and a distributed biosphere hydrological model (WEB-DHM; Wang et al. 2009a, 2009b, and 2009c) is presented as an example."

\section{Method}

\subsection{The WRF model}

The WRF model Version 2.2 (released on 22 December 2006) is currently used for the operational NWPs in Yunnan Provincial Meteorological Bureau, China. In this model, the boundary layer scheme uses the YSU (Yonsei University) scheme (Hong et al. 2006) and the microphysics is described by the WRF Single-Moment 6-Class Microphysics Scheme (WSM6H; Hong and Lim 2006). The rapid radiative transfer model (RRTM; Mlawer et al. 1997) estimates the long-wave radiation, and the scheme by Dudhia (1989) calculates the shortwave radiation. For this study, threenested domains are configured with a center at $99^{\circ} \mathrm{E}$ and $26^{\circ} \mathrm{N}$. Domain 1 is the coarsest mesh and has $60 \times 70$ grid points in the north-south and east-west directions, respectively, with a horizontal grid spacing of $90 \mathrm{~km}$. Within Domain 1, Domain 2 is nested with $61 \times 61$ grid points at $30 \mathrm{~km}$ grid spacing. The fine-mesh Domain 3 is $97 \times 97$ points with $10 \mathrm{~km}$ spatial resolution. The convection for Domains 1, 2 and 3 is described by the BettsMiller-Janjic scheme (Betts and Miller 1986; Janjic 1994), the Kain-Fritsch scheme (Kain and Fritsch 1990, 1993; Kain 2004), and the Grell-Devenyi ensemble scheme (Grell and Dévényi 2002), respectively. In this study, all the simulated results are obtained from the outputs of Domain 3. The initial boundary conditions for the WRF model are provided with the NCEP/GFS datasets (URL: ftp:// 140.90.33.31/pub/data/nccf/com/gfs/prod/), with a spatial resolution of 1 degree by 1 degree, and a temporal resolution of 3 hours.

Modern NWP data assimilation systems use various sources of information to provide a best estimate of the atmospheric state at a given time. The three-dimensional variation data assimilation (3DVAR) system (Barker et al. 2004) is currently used in the operational NWPs in Yunnan province, as well as sounding data and GPS derived precipitable water vapor, to assimilate the automatic and conventional surface meteorological observations.

\subsection{The distributed biosphere hydrological model}

A distributed biosphere hydrological model, the so-called water and energy budget baseddistributed hydrological model (WEB-DHM; Wang et al. 2009a, 2009b, 2009c), was used for the oneway coupling with the WRF model, to translate meteorological inputs into streamflows. The WEBDHM was developed by fully coupling a biosphere scheme SiB2 (Sellers et al. 1996a) with a hillslope hydrological model GBHM (Yang et al. 2002, 2004). The WEB-DHM is capable of continuously simulating the exchanges of water, energy and $\mathrm{CO}_{2}$ in the soil-vegetation-atmosphere transfer system during land-atmosphere interactions at the basinscale in a spatially-distributed manner. The model has high efficiency for the simulation of of largescale river basins, while incorporating sub-grid topography.

The overall structure of the WEB-DHM (see Fig. 2), is described as follows:

(1) A digital elevation model (DEM) is used to define the target basin, which is then divided into sub-basins (see Fig. 2a). Within a given sub-basin, a number of flow intervals are specified to represent time lags and the accumulating processes in the river network. Each flow interval includes several model grids (see Fig. 2b). It should be mentioned that Fig. 2 is a simple schematic diagram for 


\section{(a) Location of study area}

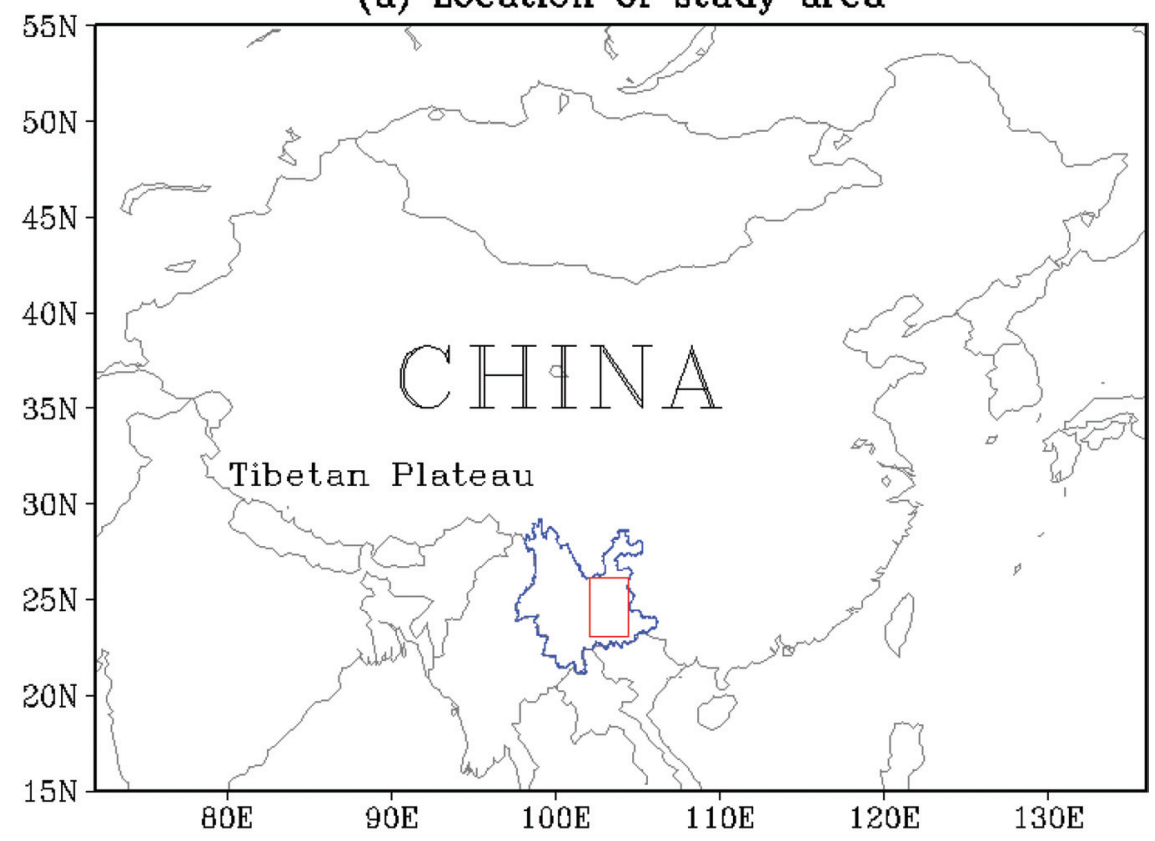

(b) Stations used in assimilation

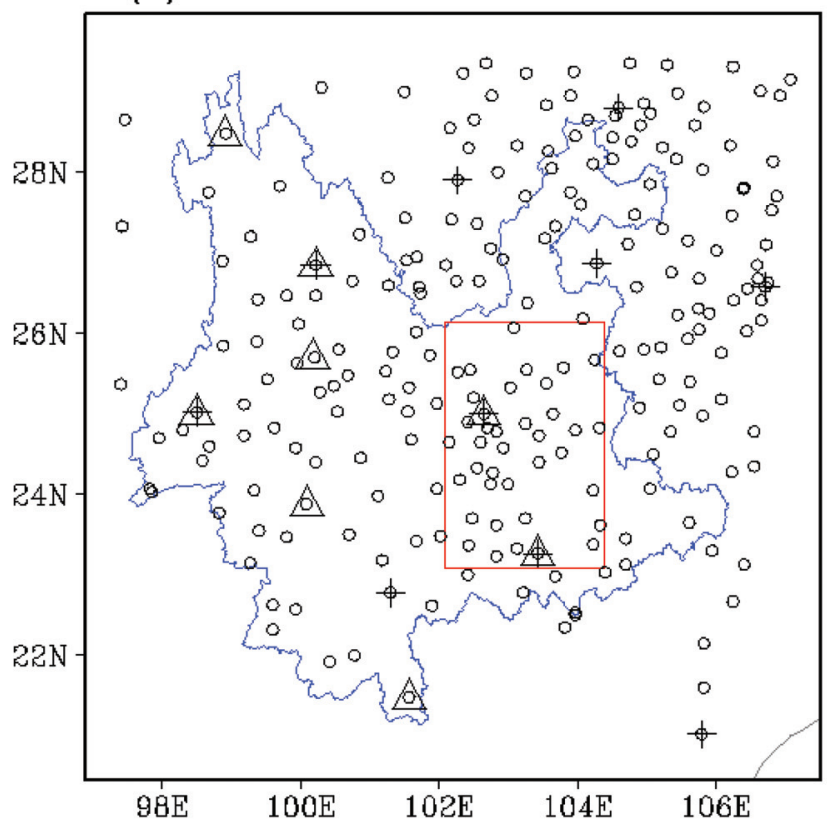

Fig. 1. Location of the Chinese Nanpan River Basin (red) in Yunnan province (blue) and the observation sites (ground-based GPS: triangle; conventional Radiosonde: cross; automatic and conventional surface observations: open circle) used for the WRF model data assimilation. 


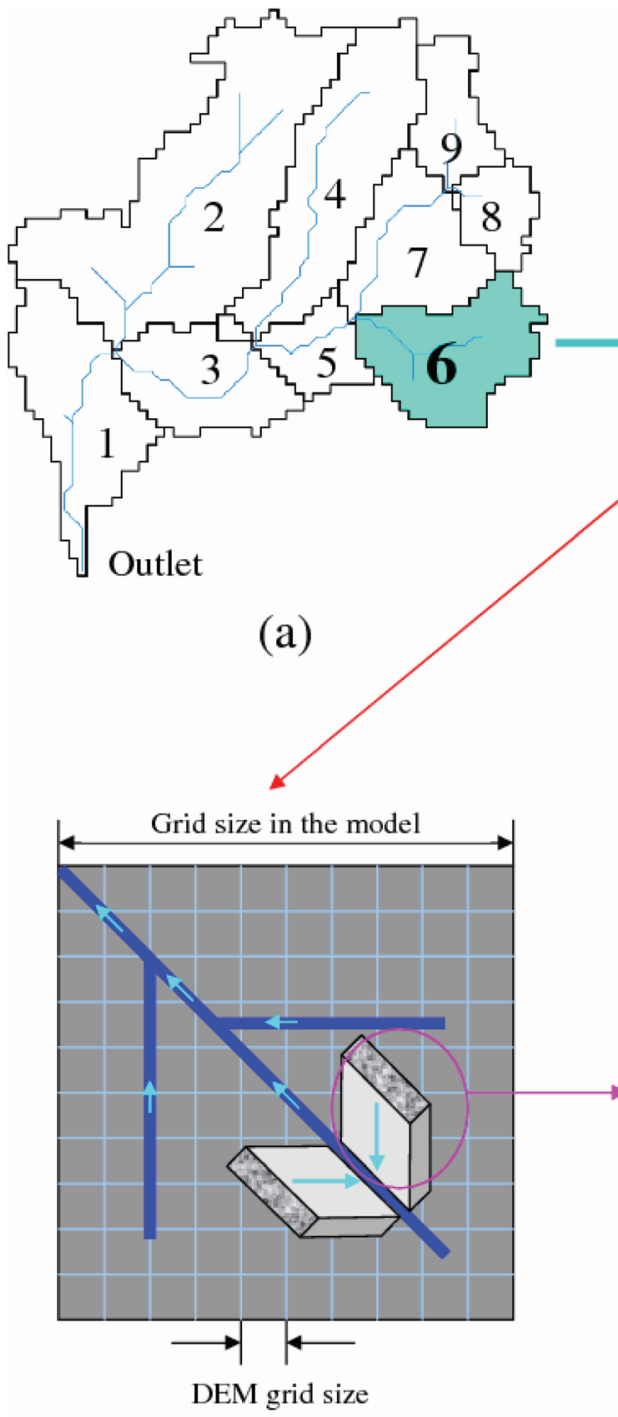

(c)

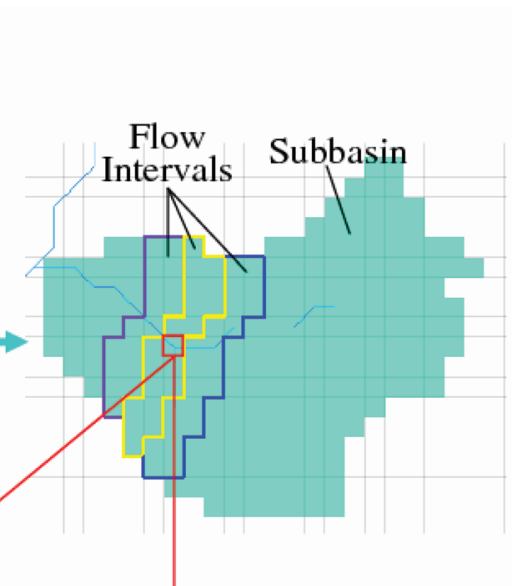

(b)

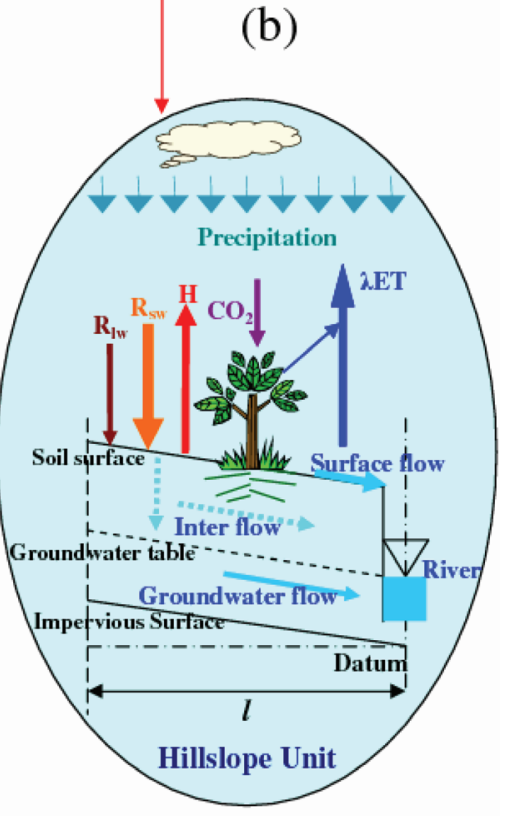

(d)

Fig. 2. Overall structure of WEB-DHM: (a) division from basin to sub-basins, (b) subdivision from subbasin to flow intervals comprising several model grids, (c) discretization from a model grid to a number of geometrically symmetrical hillslopes, and (d) description of the water moisture transfer from atmosphere to river. Where $R_{s w}$ and $R_{l w}$ are downward solar radiation and longwave radiation, respectively, $H$ is the sensible heat flux, and $\lambda$ is the latent heat of vaporization. Here, the land surface submodel is used to describe the transfer of the turbulent fluxes (energy, water, and $\mathrm{CO}_{2}$ ) between atmosphere and ground surface for each model grid; while the hydrological submodel simulates both surface and subsurface runoff using grid-hillslope discretization, and then simulates flow routing in the river network.

WEB-DHM, and does not necessarily refer to the area studied here.

(2) For each model grid with one combination of land use type and soil type, the land surface submodel independently calculates turbulent fluxes between the atmosphere and land surface (see Figs.
$2 b, d)$. The vertical distributions of water for all the model grids, such as ground interception storage and soil moisture profile, can be obtained through this biophysical process.

(3) Each model grid is subdivided into a number of geometrically symmetrical hillslopes (see Fig. 2c). 
A hillslope with unit length is called a basic hydrological unit (BHU) of the WEB-DHM. For each $\mathrm{BHU}$, the hydrological sub-model is used to simulate lateral water redistributions and calculate runoff comprising overland, lateral subsurface and groundwater flows (see Figs. 2c, d). Overland flow is described by Manning's equation, and lateral subsurface flow and groundwater discharge are simulated using Darcy's Law (Wang et al. 2009a). The runoff for a model grid is the total response of all BHUs within it.

(4) For simplicity, the streams located in one flow interval are combined into a single virtual channel. All the flow intervals are linked by the river network generated from the DEM. All runoff from the model grids in the given flow interval is accumulated into the virtual channel and led to the outlet of the river basin. The flow routing of the entire river network in the basin is modeled using the kinematic wave approach.

\section{Data}

\subsection{Hydrological data for the Nanpan River Basin}

The Nanpan River Basin (102.086 E-104.383 E, and $23.086 \mathrm{~N}-26.130 \mathrm{~N}$ ), located in Yunnan province, (see Fig. 1) is one of the eastern downstream basins of the Tibetan Plateau. It has a catchment area of $30,695 \mathrm{~km}^{2}$. The datasets of the basin as used in WEB-DHM are described as below.

Spatial data input for the WEB-DHM includes topography, land cover and soil. The DEM (Fig. 3; upper right) was obtained from SRTM 90 m Digital Elevation Data (URL: http://srtm.csi.cgiar.org/). To reduce computation cost, 90 m DEM was aggregated into a $1 \mathrm{~km}$ grid size for model simulation; while the sub-grid topography was described by the $100 \mathrm{~m}$ DEM. Digital map of $1 \mathrm{~km}$ resolution The SiB2 Land Use Map (Fig. 3b) was available from USGS (URL: http://edc2.usgs.gov/glcc/). The soil type for the basin (Fig. 3c) was obtained from the Food and Agriculture Organization (FAO 2003) together with the soil hydraulic parameters, including saturated soil moisture content, residual soil moisture content, saturated hydrologic conductivity for soil surface, and van Genuchten (1980) parameters (alpha and $n$ ). The vegetation static parameters, including morphological, optical and physiological properties, were defined following Sellers et al. (1996b). The dynamic vegetation parameters, Leaf Area Index (LAI), and the Fraction of Photosynthetically Active Radiation (FPAR) absorbed by the green vegetation canopy can be obtained from satellite data. Global LAI and FPAR MOD15_BU 0.25 degree data sets (Myneni et al. 1997) were used in this study. These are 8-daily composites of MOD15A2 products and are from the Warehouse Inventory Search Tool (WIST) of NASA.

Hourly observed precipitation data from 96 rain gauges (Fig. 3a) were obtained by the Yunnan Institute of Meteorology (YIM), China Meteorological Administration. Due to the data availability, and the small influence of short-term evapotranspiration on the simulations of flash floods, the observed hourly air temperature, relative humidity, air pressure, wind speed, and sunshine duration obtained from one YIM meteorological site (Xiqiao) are used in the whole-basin simulation in this study. Downward solar radiation was estimated from sunshine duration, temperature, and humidity following Yang et al. (2001, 2006). Long wave radiation was then estimated from temperature, relative humidity, pressure, and solar radiation following Crawford and Duchon (1999). The surface air temperature inputs are modified with a lapse rate of $6.5 \mathrm{~K} \mathrm{~km}^{-1}$, considering the elevation differences between the model grids and meteorological stations.

\subsection{Integrated observations for $3 D V A R$ in Yunnan province}

As shown in Fig. 1b, (for Domain 3 covering the Yunnan province, 96.9 E-107.52 E, and $20.46 \mathrm{~N}-$ $29.955 \mathrm{~N}$ ), the assimilated observations comprise the data from the automatic and conventional surface observations (air temperature, air pressure, relative humidity, wind direction and speed, precipitation) at 230 sites, the sounding data (air temperature, air pressure, relative humidity, wind direction and speed, and dew point temperature) at the standard radiosonde layers defined by World Meteorological Organization (WMO) from 10 conventional Radiosonde sites, and the total precipitable water vapor from 8 ground-based GPS stations. Based on these observations, seven scenarios have been designed for the WRF-3DVAR (see Table 1), to investigate the contributions of the different sources of observations to the accuracy of QPFs.

\section{Results and discussions}

The heavy-rain event of 01-02 July 2008 at Kunming City (the capital of Yunnan province, see Fig. 3a) recorded $117.2 \mathrm{~mm}$ rainfall in $24 \mathrm{~h}$ (00:00 UTC 01 July to 00:00 UTC 02 July), and is the third-largest heavy-rain in the city's history. 


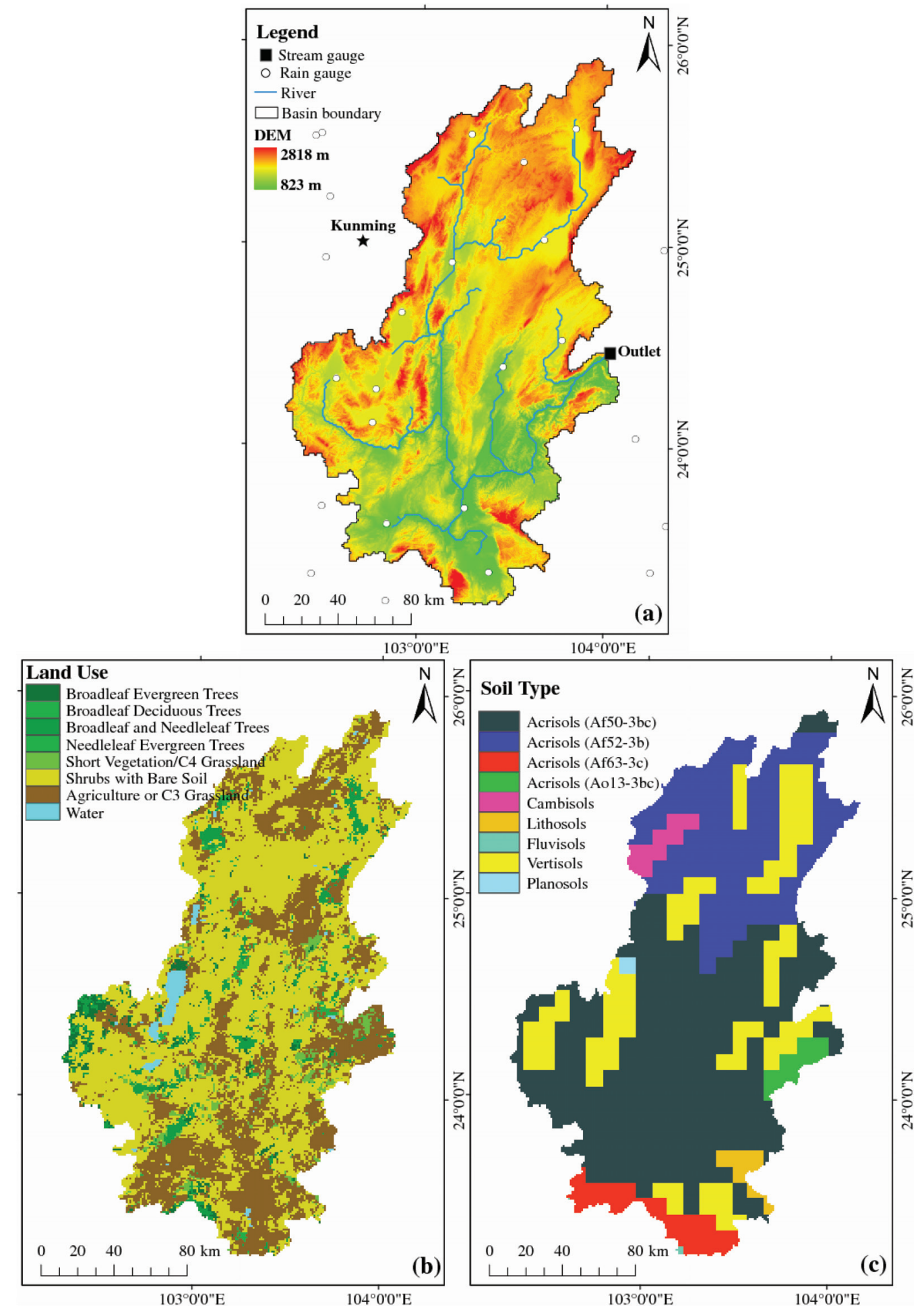

Fig. 3. Datasets for the Nanpan River Basin: discharge and rain gauges as well as DEM (a), land use (b), and soil (c). The basin area is $30,695 \mathrm{~km}^{2}$. 

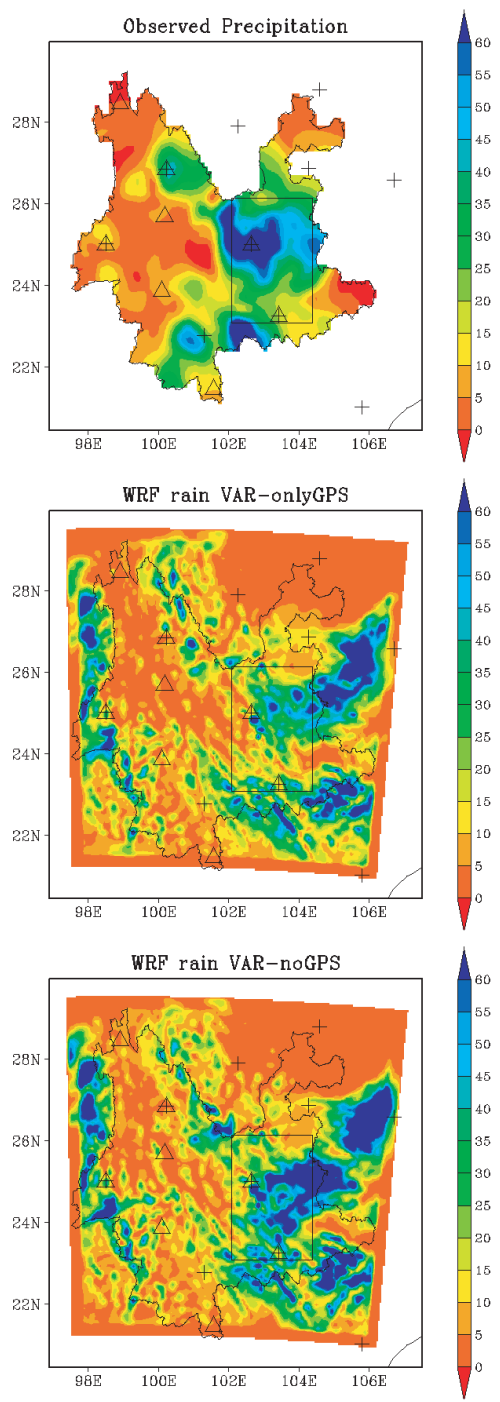
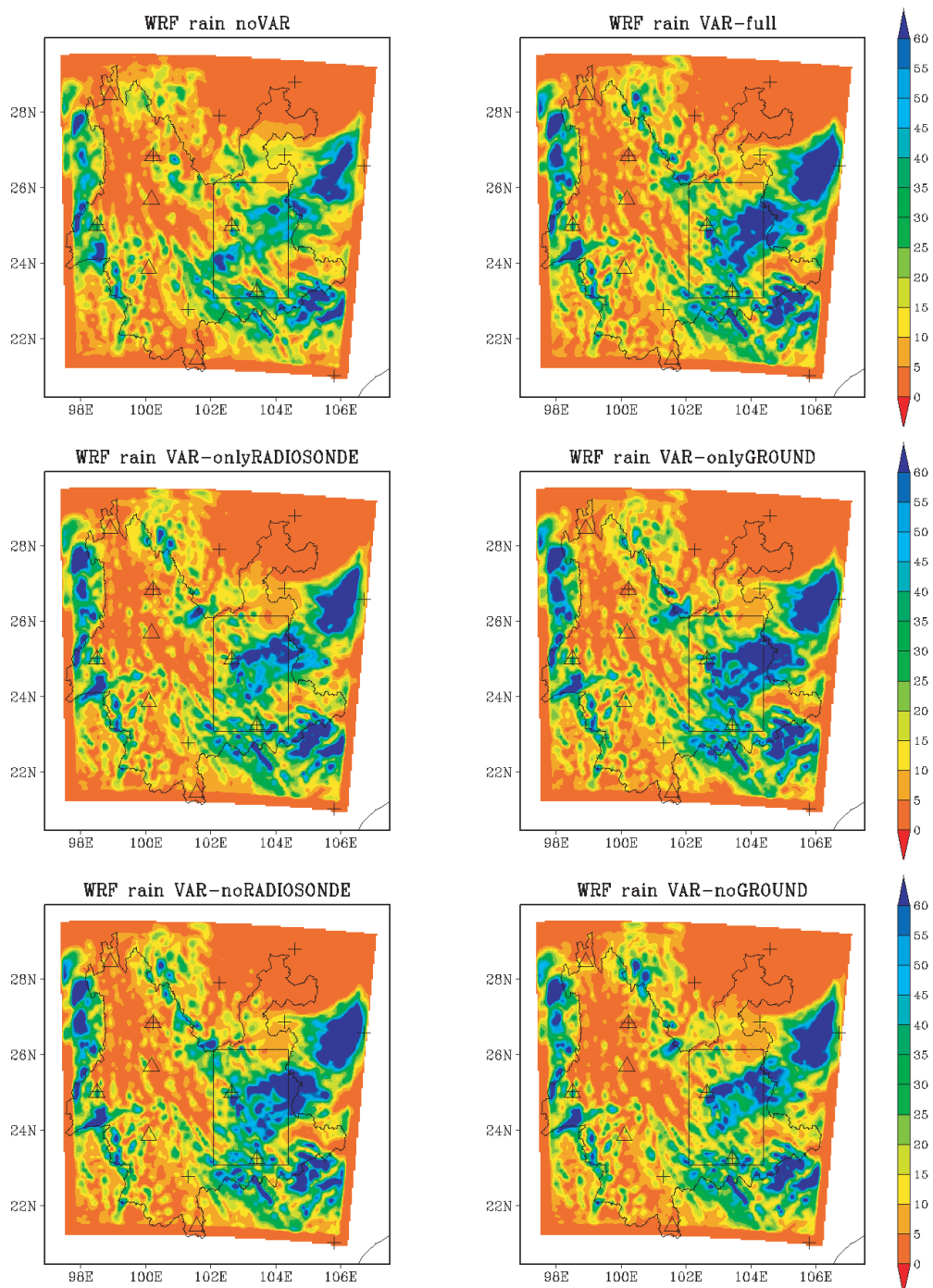

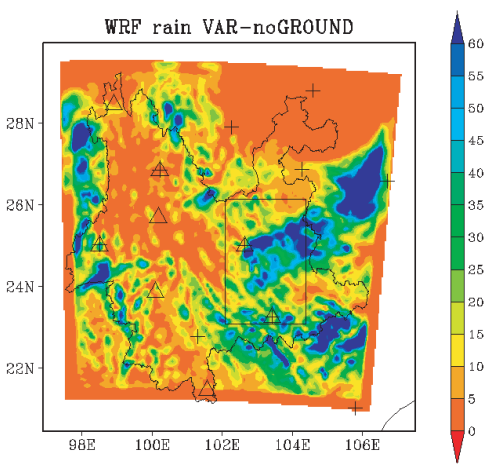

Fig. 4. Observed 0-36 h total rainfall comparing to the WRF-forecasted rainfall (Unit: mm) without or with data assimilation in the rectangle region $(96.9 \mathrm{E}-107.52 \mathrm{E}$, and $20.46 \mathrm{~N}-29.955 \mathrm{~N})$, covering the whole Yunnan province. Where, GPS and Radiosonde sites are indicated in "triangle" and "cross", respectively.

Hence, this date was chosen to test the 36-h realtime flood forecasting with the WRF and WEBDHM. Results from the WRF with the assimilation of the meteorological observations (hereafter "WRF-3DVAR") and the WRF without data assimilation (hereafter "WRF-noVAR"), are compared to the rain-gauge observations.

Figure 4 displays the spatial patterns of the $0-$ $36 \mathrm{~h}$ WRF forecasted rainfall without or with the 3DVAR, comparing to rain gauge data for the rectangle region $(96.9 \mathrm{E}-107.52 \mathrm{E}$, and $20.46 \mathrm{~N}-$ $29.955 \mathrm{~N})$. Broadly this covers the Yunnan province. Comparing to the pattern and magnitude of the observed rainfall, the WRF-noVAR obviously underestimates the $0-36 \mathrm{~h}$ accumulated rainfall that covers the eastern part of Yunnan province; while all the WRF-3DVAR scenarios demonstrate better performances in QPFs although the WRF-3DVAR forecasted heavy-rain patterns are shifted slightly to the east. Among all the WRF3DVAR scenarios (see Table 1), VAR-full, VARonlyGROUND, VAR-noGPS, as well as VARnoRADIOSONDE generally illustrates higher accuracies than the other three WRF-3DVAR scenarios (VAR-onlyGPS, VAR-onlyRADIOSONDE, and VAR-noGROUND). This shows that the 230- 
Table 1. Scenarios designed for the WRF-3DVAR.

\begin{tabular}{|c|c|c|c|c|}
\hline \multirow[b]{2}{*}{ ID } & \multirow[b]{2}{*}{ Scenario } & \multicolumn{3}{|c|}{ Datasets used in the WRF-3DVAR (Assimilated variables) } \\
\hline & & $\begin{array}{l}8 \text { ground-based } \\
\text { GPS sites } \\
\text { (total precipitable } \\
\text { water vapor) }\end{array}$ & $\begin{array}{l}10 \text { conventional } \\
\text { Radiosonde sites } \\
\text { (vertical profiles of air } \\
\text { temperature, air pressure, } \\
\text { relative humidity, wind } \\
\text { direction and speed, and } \\
\text { dew point temperature) }\end{array}$ & $\begin{array}{c}230 \text { automatic and } \\
\text { conventional surface } \\
\text { observation sites } \\
\text { (air temperature, } \\
\text { air pressure, relative } \\
\text { humidity, wind direction } \\
\text { and speed, precipitation) }\end{array}$ \\
\hline & VAR-full & $\checkmark$ & $\checkmark$ & $\checkmark$ \\
\hline & VAR-onlyGPS & $\checkmark$ & & \\
\hline & VAR-onlyRADIOSONDE & & $\checkmark$ & \\
\hline & VAR-onlyGROUND & & & $\checkmark$ \\
\hline & VAR-noGPS & & $\checkmark$ & $\checkmark$ \\
\hline & VAR-noRADIOSONDE & $\checkmark$ & & $\checkmark$ \\
\hline & VAR-noGROUND & $\checkmark$ & $\checkmark$ & \\
\hline
\end{tabular}

site automatic and conventional surface observations are crucial in the WRF-3DVAR simulations. The 10-site conventional sounding data and the 8site GPS total precipitable water vapor also contribute to the QPFs in the WRF-3DVAR simulations.

Figure 5 shows the interpolated rainfall $(1 \mathrm{~km}$ resolution) from the rain gauges and the WRF model outputs (from WRF-noVAR and seven WRF-3DVAR scenarios), for the rectangular region $(102.086 \mathrm{E}-104.383 \mathrm{E}$, and $23.086 \mathrm{~N}-$ $26.130 \mathrm{~N}$ ), this covers the Nanpan River Basin. When considering both the precipitation magnitude and spatial distributions, this further confirms the better performance of QPFs by the WRF-3DVAR over the WRF-noVAR. It should be noted that VAR-onlyGPS have a comparably poor performance (especially for the spatial pattern of rainfall) with WRF-noVAR. This is not surprising since VAR-onlyGPS assimilated only the initial observations (total precipitable water vapor at 00:00 UTC 01 July, hereafter GPS-V) from two ground-based GPS stations (see Fig. 5). Hence it is necessary to update the 3DVAR to 4DVAR (e.g., Gauthier et al. 2007) to allow increased assimilated data volume (e.g., the GPS observations in other periods) for the operational NWPs in Yunnan province. The VAR-onlyRADIOSONDE assimilated the 10site radiosonde observations, including the vertical profiles of air temperature, air pressure, relative humidity, wind direction and speed, and dew point temperature (hereafter Radio-V), while the VAR-
onlyGROUND assimilated the 230-site surface observations, including air temperature, air pressure, relative humidity, wind direction and speed, and precipitation (hereafter Surface-V). The VARonlyGROUND has shown slightly better performance than the VAR-onlyRADIOSONDE, while both of them are much better than the VARonlyGPS. This has shown that not only the assimilated variables, but also their spatial coverage (e.g., the number of observational sites, and the number of vertical layers) are crucially important in the WRF-3DVAR, since the latter provides valuable information for the spatial heterogeneity (in both the vertical and horizontal) of the assimilated variables. This can improve the initial fields for WRF simulations. The scenarios of VAR-noGPS, VARnoRADIOSONDE, and VAR-noGROUND have demonstrated inferior performances compared to VAR-noGPS and the VAR-noGROUND. This further confirmed the higher importance of Surface-V over Radio-V and the higher importance of Radio-V over GPS-V in this study. VAR-full has not performed as well as some of the other 3DVAR scenarios, showing that increased assimilated data does not necessarily improve the accuracy of $\mathrm{QPF}$, but instead the $\mathrm{QPF}$ requires theoretical improvements in the WRF-3DVAR.

Figure $6 \mathrm{a}$ shows the hourly basin-averaged precipitation comparisons between the observation and the WRF forecasts (WRF-noVAR and seven WRF-3DVAR scenarios) from 00:00 UTC 01 July 

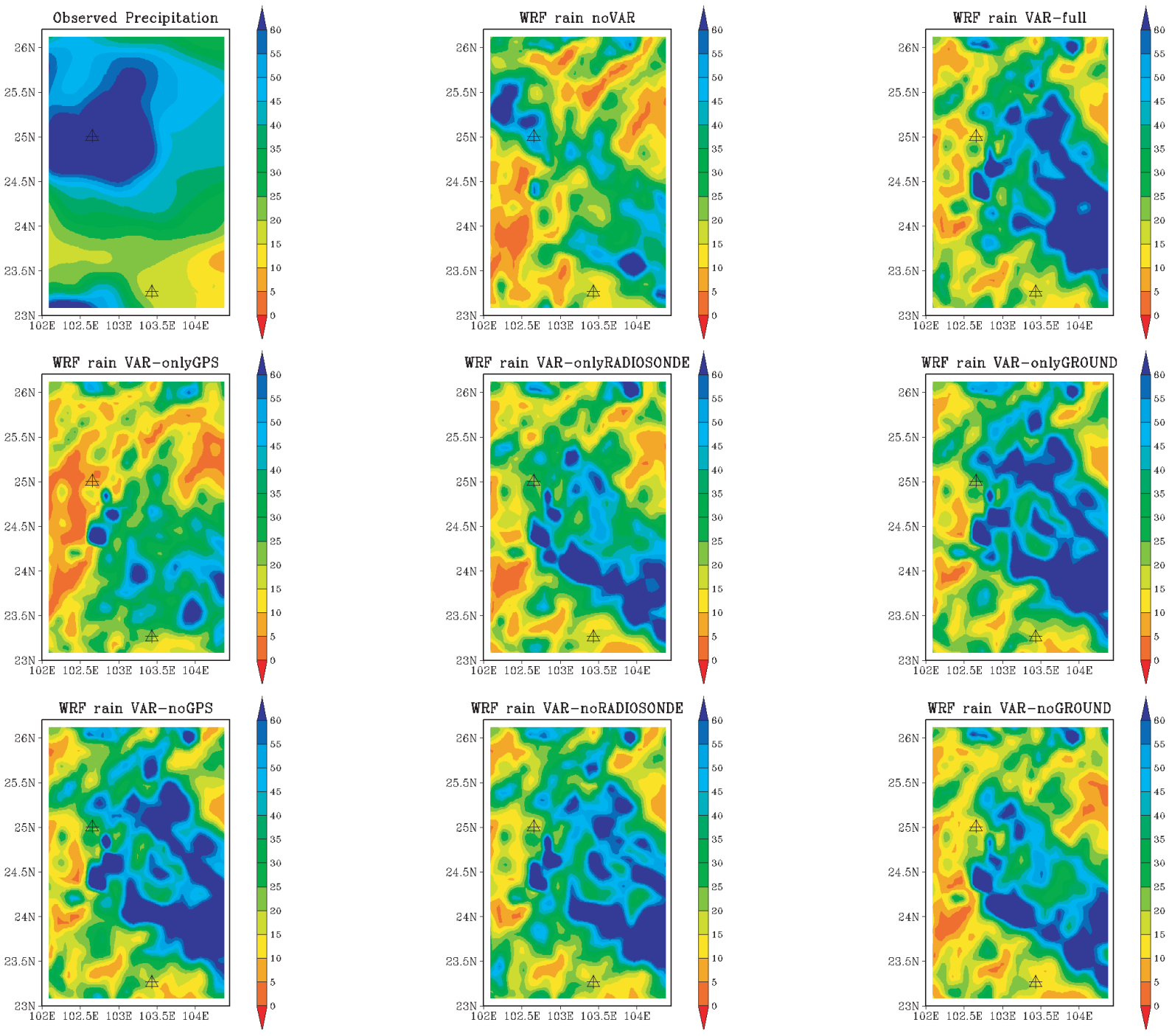

Fig. 5. The interpolated rainfall $(1 \mathrm{~km}$ resolution) from the rain gauges and the WRF model outputs (from WRF-noVAR and seven WRF-3DVAR scenarios), for the rectangle region (102.086 E-104.383 E, and 23.086 N-26.130 N) that covers the Nanpan River Basin. Where, the GPS and Radiosonde sites are indicated by "triangle" and "cross", respectively.

to 12:00 UTC 02 July 2008. For the Nanpan River Basin, in general the WRF-3DVAR scenarios show acceptable accuracies in predicting the basinaveraged hourly rainfall (close to the observed rainfall), except for the obvious under-predictions in the last 9 hours (3:00 to 12:00 UTC 02 July). This may be because the WRF-3DVAR used in this study only assimilated the initial observations (from the GPS/RADIOSONDE/GROUND variables) at 00:00 UTC 01 July. VAR-onlyGPS predicts better peak rainfall (in terms of time and magnitude) than WRF-noVAR, although both of them underpredict the peaks that occurred from 20:00 to 21:00 UTC 01 July.

Figure $6 \mathrm{~b}$ is similar to Fig. 6a, except it shows the accumulated values averaged in the Nanpan River Basin. As previously, the $0-36 \mathrm{~h}$ basinaveraged total rainfall is generally well predicted by all the WRF-3DVAR scenarios (from $34.5 \mathrm{~mm}$ to $43.4 \mathrm{~mm}$ vs $44.0 \mathrm{~mm}$ ). VAR-onlyGPS did not perform as well as the others $(27.6 \mathrm{~mm})$, but still performed better than WRF-noVAR $(22.5 \mathrm{~mm})$. 

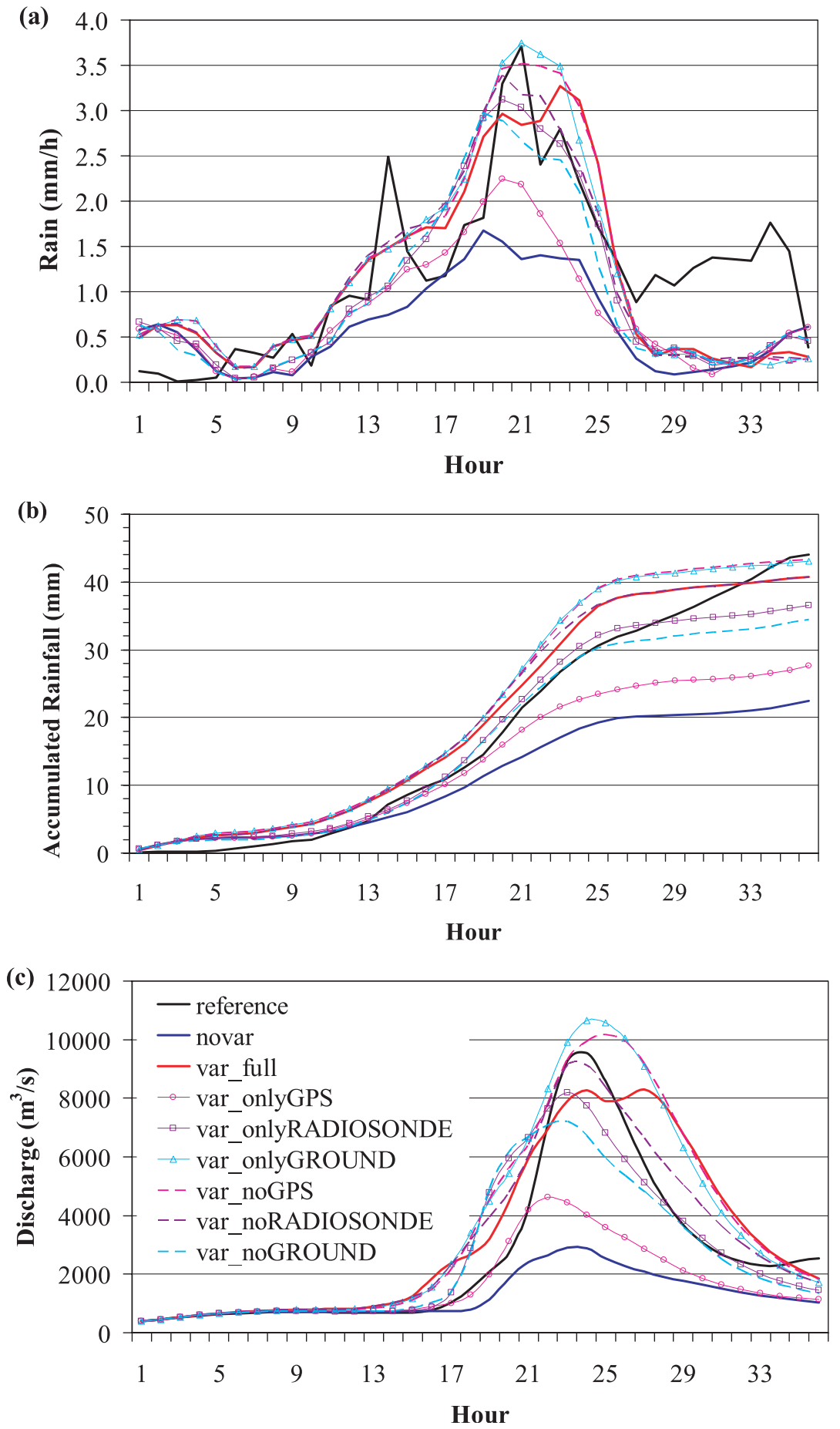

Fig. 6. Basin-averaged precipitation comparisons between observation with WRF forecasts without or with data assimilations ( $\mathrm{a}$ and $\mathrm{b}$ ); and the predicted discharges by WEB-DHM using these different sources of inputs (c) at the outlet of the Nanpan River Basin from 00:00 UTC 01 July to 12:00 UTC 02 July 2008. 
VAR-noGROUND and VAR-onlyRADIOSONDE both predicted the accumulated 0-26 h (00:00 UTC 01 July to 2:00 UTC 02 July) rainfall very well (30.9 $\mathrm{mm}$ and $33.1 \mathrm{~mm}$, vs $32.0 \mathrm{~mm}$ ). This has demonstrated that in the WRF-3DVAR simulations, the 10-site conventional sounding data also plays an important role for QPFs in the basin. This is reasonable since the sounding data provides the vertical profiles of six important meteorological elements (air temperature, air pressure, relative humidity, wind direction and speed, and dew point temperature).

Figure $6 \mathrm{c}$ gives the $0-36 \mathrm{~h}$ flood forecasts for the outlet of the Nanpan River Basin from 00:00 UTC 01 July to 12:00 UTC 02 July 2008. Fed with the different sources of rainfall from WRF forecasts, the WEB-DHM has produced different flood forecasts at the basin outlet. Due to the availability of hourly discharge data, the simulated hourly discharge (with a peak value of $9555 \mathrm{~m}^{3} \mathrm{~s}^{-1}$ at 00:00 UTC 02 July) has been used as a reference for evaluating the other simulated discharges in this study. Results show that the simulated floods by the WEB-DHM forced with the WRF-3DVAR forecasts, generally show reasonable responses to the heavy rainfall event (21:00 UTC 01 July) except VAR-onlyGPS, predicting flood peaks from $7211 \mathrm{~m}^{3} \mathrm{~s}^{-1}$ (at 23:00 UTC 01 July; by VARnoGROUND) to $10651 \mathrm{~m}^{3} \mathrm{~s}^{-1}$ (at 00:00 UTC 02 July; by VAR-onlyGROUND). Although VARonlyGPS performs less well (with a flood peak of $4617 \mathrm{~m}^{3} \mathrm{~s}^{-1}$ at 22:00 UTC 01 July) than the other six WRF-3DVAR scenarios, it still can provide useful information to water resources managers for the flood disaster warning and prevention. As expected, the one simulated with the WRFnoVAR forecasts, shows the smallest flood peak $\left(2898 \mathrm{~m}^{3} \mathrm{~s}^{-1}\right)$ due to the large under-prediction of rainfall in the basin.

\section{Conclusions}

In this study, an atmosphere-hydrology system (WRF2.2 coupled with WEB-DHM) has been developed and applied to the short-term flood forecasting in the Nanpan River Basin (southeast to Tibetan Plateau) on 1 July 2008. In the WRF3DVAR simulations, the assimilated observations comprise the data from the automatic and conventional surface observations at 230 sites, the sounding data from 10 conventional Radiosonde sites, and the total precipitable water vapor from eight ground-based GPS stations. Based on these ob- servations, seven scenarios were designed for the WRF-3DVAR to investigate the contributions of the different sources of observations to the $0-36 \mathrm{~h}$ real-time QPFs, and thus short-term streamflow forecasting. To our knowledge, this work is the first to utilize comprehensive observations (e.g., Radiosonde and GPS) around the Tibetan Plateau to improve short-term flood predictions with a coupled atmosphere-hydrology system. The major conclusions and are:

First, the overall better performance of QPFs by the WRF-3DVAR over the WRF-noVAR has been demonstrated in terms of both the rainfall magnitude and spatial distribution.

Second, the 230-site automatic and conventional surface observations are crucial in the WRF3DVAR simulations, although the 10-site conventional sounding data and the 8-site GPS total precipitable water vapor also significantly contribute to the accuracy of QPFs in the WRF-3DVAR simulations.

Third, although VAR-onlyGPS performs less well (predicting a flood peak of $4617 \mathrm{~m}^{3} \mathrm{~s}^{-1}$ at the basin outlet, two hours early) than the other six WRF-3DVAR scenarios (predicting peak values from $7211 \mathrm{~m}^{3} \mathrm{~s}^{-1}$ to $\left.10651 \mathrm{~m}^{3} \mathrm{~s}^{-1}\right)$, it still provides crucial information to water resources managers for flood disaster warning and prevention. This further confirms the superiority of WRF-3DVAR to WRF-noVAR (which predicted a flood peak of $\left.2898 \mathrm{~m}^{3} \mathrm{~s}^{-1}\right)$.

Finally, the poorest performance of VARonlyGPS among all the seven WRF-3DVAR scenarios, shows the necessity of further improving the assimilation techniques, e.g., to update the 3DVAR to 4DVAR for the operational QPFs in Yunnan province.

\section{Acknowledgements}

This study was jointly supported by the China and Japan intergovernmental cooperation program funded by Japan International Cooperation Agency (JICA), and the social commonweal research program of Ministry of Science and Technology of the People's Republic of China (grant number: 2005DIB3J057). The third author (Man Wang) was supported by the opening foundation of $\mathrm{Wu}-$ han Institute of Heavy Rain, CMA (grant number: IHR2005G02) and the applied basic research foundation of Yunnan province, China (General Program, grant number: 2009CD145); while the fifth author (Jihua Sun) was funded by the Yunnan pro- 
vincial research institute and provincial university science and technology cooperation plan (grant number: 2006YX39).

\section{References}

Amengual, A., T. Diomede, C. Marsigli, A. Martin, A. Morgillo, R. Romero, P. Papetti, and S. Alonso, 2008: A hydrometeorological model intercomparison as a tool to quantify the forecast uncertainty in a medium size basin. Nat. Hazards Earth Syst. Sci., 8, 819-838.

Barker, D. M., W. Huang, Y. Guo, A. J. Bourgeois, and Q. Xiao, 2004: A three-dimensional variational data assimilation system for MM5: implementation and initial results. Mon. Weather Rev., 132, 897-914.

Benoit, R., N. Kouwen, W. Yu, S. Chamberland, and P. Pellerin, 2003: Hydrometeorological aspects of the Real-Time Ultrafinescale Forecast Support during the Special Observing Period of the MAP*. $\mathrm{Hy}$ drol. Earth Syst. Sci., 7, 877-889, doi:10.5194/ hess-7-877-2003.

Betts, A. K., and M. J. Miller, 1986: A new convective adjustment scheme. Part II: Single column tests using GATE wave, BOMEX, ATEX and Arctic air-mass data sets. Quart. J. Roy. Meteor. Soc., 112, 693-709.

Chinese Academy of Meteorological Sciences (CAMS), State Key Laboratory on Severe Weather, JICA Project Executive Panel, 2009: a progress report on JICA project of China-Japan Cooperation on the New Integrated Meteorological Observation Network on the Qinghai-Tibetan Plateau and its adjacent areas, and the disaster early warning techniques, part 5, $66 \mathrm{pp}$.

Crawford, T. M., and C. E. Duchon, 1999: An improved parameterization for estimating effective atmospheric emissivity for use in calculating daytime downwelling longwave radiation. J. Appl. Meteorol., 38, 474-480.

De Roo, A. P. J., B. Gouweleeuw, J. Thielen, J. Bartholmes, P. Bongioannini-Cerlini, E. Todini, P. D. Bates, M. Horritt, N. Hunter, K. Beven, F. Pappenberger, E. Heise, G. Rivin, M. Hils, A. Hollingsworth, B. Holst, J. Kwadijk, P. Reggiani, M. V. Dijk, K. Sattler, and E. Sprokkereef, 2003: Development of a European flood forecasting system. Intl. J. River Basin Management, 1(1), 49-59.

Diomede, T., C. Marsigli, F. Nerozzi, P. Papetti, and T. Paccagnella, 2008: Coupling high-resolution precipitation forecasts and discharge predictions to evaluate the impact of spatial uncertainty in numerical weather prediction model outputs. Meteorol. Atmos. Phys., 102, 37-62.
Dudhia, J., 1989: Numerical study of convection observed during the winter monsoon experiment using a meso-scale two-dimensional model. J. Atmos. Sci., 46, 3077-3107.

FAO, 2003: Digital soil map of the world and derived soil properties. Land and Water Digital Media Series Rev. 1, United Nations Food and Agriculture Organization, CD-ROM.

Gauthier, P., M. Tanguay, S. Laroche, and S. Pellerin, 2007: Extension of 3DVAR to 4DVAR: Implementation of 4DVAR at the Meteorological Service of Canada. Mon. Weather Rev., 135, 2339-2354.

Grell, G. A., and D. Dévényi, 2002: A generalized approach to parameterizing convection combining ensemble and data assimilation techniques. Geophys. Res. Lett., 29(14), 1693, doi:10.1029/ 2002 GL015311.

Hong, S. Y., and J. J. Lim, 2006: The WRF singlemoment 6-class microphysics scheme (WSM6). $J$. Korean Meteor. Soc., 42, 129-151.

Hong, S. Y., Y. Noh, and J. Dudhia, 2006: A new vertical diffusion package with an explicit treatment of entrainment processes. Mon. Weather Rev., 134(9), $2318-2341$

Janjic, Z. I., 1994: The step-mountain Eta coordinate model: Further developments of the convection, viscous sublayer, and turbulence closure schemes. Mon. Wea. Rev., 122, 927-945.

Kain, J. S., 2004: The Kain-Fritsch convective parameterization: An update. J. Appl. Meteorol., 43, 170181.

Kain, J. S., and J. M. Fritsch, 1990: A one-dimensional entraining/detraining plume model and its application in convective parameterization. J. Atmos. Sci. 47, 2784-2802.

Kain, J. S., and J. M. Fritsch, 1993: Convective parameterization for mesoscale models: The Kain-Fritsch scheme, 165-170 in The representation of cumulus convection in numerical models, Emanuel K. A., Raymond D. J., (eds). Meteorol. Monogr. No. 46. Amer. Meteorol. Soc

Lettenmaier, D. P., A. de Roo, and R. Lawford, 2006: Towards a capability for global flood forecasting. WMO Bulletin, 55(3), 185-190.

Lin, C. A., L. Wen, M. Béland, and D. Chaumont, 2002 A coupled atmospheric-hydrological modeling study of the $1996 \mathrm{Ha}$ ! Ha! River basin flash flood in Québec, Canada. Geophys. Res. Lett., 29(2), 10.1029/2001GL013827.

Ma, X., T. Yoshikane, M. Hara, Y. Wakazuki, H. G. Takahashi, and F. Kimura, 2010: Hydrological response to future climate change in the Agano River basin, Japan. Hydrological Research Letters, 4, 25-29.

Ma, Y., S. Kang, L. Zhu, B. Xu, L. Tian, and T. Yao, 2008: Tibetan Observation and Research Plat- 
form: atmosphere-land interaction over a heterogeneous landscape. B. Am. Meteorol. Soc., 89, 14871492.

McGuire, M., A. W. Wood, A. F. Hamlet, and D. P. Lettenmaier, 2006: Use of satellite data for streamflow and reservoir storage forecasts in the Snake River Basin. J. Water Res. Pl.-ASCE, 132, 97-110.

Mlawer, E. J., S. J. Taubman, P. D., Brown, M. J. Iacono, and S. A. Clough, 1997: Radiative transfer for inhomogeneous atmosphere: RRTM, a validated correlated k-model for the longwave. J. Geophys. Res., 102(D14), 16663-16682.

Myneni, R. B., R. R. Nemani, and S. W. Running, 1997: Algorithm for the estimation of global land cover, LAI and FPAR based on radiative transfer models. IEEE T. Geosci. Remote, 35, 1380-1393.

Sellers, P. J., D. A. Randall, G. J. Collatz, J. A. Berry, C. B. Field, D. A. Dazlich, C. Zhang, G. D. Collelo, and L. Bounoua, 1996a: A revised land surface parameterization (SiB2) for atmospheric GCMs, Part I: Model Formulation. J. Climate, 9, 676-705.

Sellers, P. J., S. O. Los, C. J. Tucker, C. O. Justice, D. A. Dazlich, G. J. Collatz, and D. A. Randall, 1996b: A revised land surface parameterization $(\mathrm{SiB} 2)$ for atmospheric GCMs, Part II: The generation of global fields of terrestrial biophysical parameters from satellite data. J. Climate, 9, 706-737.

Skamarock, W. C., J. B. Klemp, J. Dudhia, D. O. Gill, D. M. Barker, W. Wang, and J. G. Powers, 2005: A description of the Advanced Research WRF version 2, NCAR Tech. Note NCAR/TN-468_STR, $88 \mathrm{pp}$.

United Nations University, 2004: Two Billion People Vulnerable to Floods by 2050; Number Expected to Double or More in Two Generations Due to Climate Change, Deforestation, Rising Seas, Population Growth (News Release), http://www.unu .edu/news/ehs/floods.doc

van Genuchten, M. Th. (1980), A closed-form equation for predicting the hydraulic conductivity of unsaturated soils. Soil Sci. Soc. Am. J., 44, 892-898.

Wang, L., T. Koike, K. Yang, T. Jackson, R. Bindlish, and D. Yang, 2009a: Development of a distributed biosphere hydrological model and its evaluation with the Southern Great Plains Experiments (SGP97 and SGP99). J. Geophys. Res.-Atmos., 114, D08107, doi:10.1029/2008JD010800.

Wang, L., T. Koike, K. Yang, and P. Yeh, 2009b: Assessment of a distributed biosphere hydrological model against streamflows and MODIS land surface temperature in the upper Tone River Basin. J. Hydrol., 377, 21-34.

Wang, L., T. Koike, D. Yang, and K. Yang, 2009c: Improving the hydrology of the Simple Biosphere
Model 2 and its evaluation within the framework of a distributed hydrological model. Hydrolog. Sci. J., 54(6), 989-1006.

Wang, M., H. Li, X. Duan, and J. Liu, 2009: Structure analysis and numerical simulation of a landing Bengal Strom. Meteorological Science and Technology, 37(1), 12-18. (in Chinese)

Weisman, M. L., C. Davis, W. Wang, K. W. Manning, and J. B. Klemp, 2008, Experiences with 0-36-h explicit convective forecasts with the WRF model. Weather Forecast., 23(3), 407-437.

Xu, X., C. Lu, X. Shi, and S. Gao, 2008a: World water tower: An atmospheric perspective. Geophys. Res. Lett., 35, L20815, doi: 10.1029/2008GL035867.

Xu, X., R. Zhang, K. Toshio, C. Lu, X. Shi, S. Zhang, L. Bian, X. Cheng, P. Li, and G. Ding, 2008b: A New Integrated Observational System over the Tibetan Plateau. B. Am. Meteorol. Soc., 89, 1492 1496.

Xu, X., X. Y. Shi, Y. Wang, S. Peng, and X. H. Shi, 2008c: Data analysis and numerical simulation of moisture source and transport associated with summer precipitation in the Yangtze River Valley over China. Meteorol. Atmos. Phys., 100, 217-231.

Yang, D., S. Herath, and K. Musiake, 2002: A hillslopebased hydrological model using catchment area and width functions. Hydrol. Sci. J., 47(1), 49-65.

Yang, D., T. Koike, and H. Tanizawa, 2004: Application of a distributed hydrological model and weather radar observation for flood management in the upper Tone River of Japan. Hydrol. Process., 18, 3119-3132, doi:10.1002/hyp.5752.

Yang, K., G. Huang, and N. Tamai, 2001: A hybrid model for estimating global solar radiation. Sol. Energy, 70, 13-22.

Yang, K., T. Koike, and B. Ye, 2006: Improving estimation of hourly, daily, and monthly solar radiation by importing global data set. Agr. Forest Meteorol., 137, 43-55.

Yu, Z., M. N. Lakhtakia, B. Yarnal, R. A. White, D. A. Miller, B. Frakes, E. J. Barron, C. Duffy, and F. W. Schwartz, 1999: Simulating the river basin response to atmospheric forcing by linking a mesoscale meteorological model and hydrological model system. J. Hydrol., 218, 72-91.

Zhang, C., M. Chen, Y. H. Kuo, S. Fan, and J. Zhong, 2005: Numerical assessing experiments on the individual components impact of the meteorological observation network on the "00.7" torrential rain in Beijing. Acta Meteorol. Sin., 63(6), 922932.

Zhao, Q., Z. Liu, B. Ye, Y. Qin, Z. Wei, and S. Fang, 2009: A snowmelt runoff forecasting model coupling WRF and DHSVM. Hydrol. Earth Syst. Sci., 13, 1897-1906, doi:10.5194/hess-13-1897-2009. 